\title{
WHEN BENEFITS ARE DIFFICULT TO MEASURE
}

\author{
William C. BiRDSAlL \\ University of Michigan
}

\begin{abstract}
Benefit cost analysis is seldom applied to programs which aim directly at improving human well-being; the problems in quantifying such benefits, particularly in dollar form, are simply too great. This paper explains "threshold benefit analysis," the derivation of the minimum dollar value which the benefits must attain in order for the value of the benefits to equal the cost of the intervention. As an example, the method is applied to a mobility training program. The threshold benefit of such training is approximately two dollars per commute. The empirical results include a sensitivity analysis which allows considerable flexibility on the part of potential users. The methodology is applicable to analyzing any intervention where costs are incurred early, initial "successes" can be counted in natural numbers, and duration of success can be modelled simply.
\end{abstract}

Benefit cost analysis of human service programs is, like virtue, more praised than practiced. One reason for this is the gulf between our ability to measure the costs of an intervention versus the benefits from the intervention. The former can usually be measured with reasonable accuracy; the latter seldom, especially for programs designed to improve human well-being directly. Subjective or intangible benefits are typically an important outcome of human service programs that are rarely reliably measured, especially in dollar terms. For such programs the transformation of beneficial outcomes into dollars is often flimsy at best; arguments to double or halve the estimate are as cogent as arguments for the initial estimate. When this is true, there is plausibility to the judgment that benefit cost analysis is merely an exercise in psuedo-scientific measurement, that doing nothing is both more helpful and more honest.

In this paper I will argue and exemplify that the choice is not necessarily between simply giving up or perpetrating a sham. There is a respectable third possibility, which is to estimate the threshold benefit. ${ }^{1}$

"See Nagel (1983) who develops the concept of "threshold analysis" when one or more variables in the benefit cost framework are unknown.
The threshold benefit is the minimum dollar value which the benefits must attain in order for the value of the benefits to equal the cost of the intervention. This can, in the author's opinion, virtually always be measured with considerable accuracy and is usually more than sufficient to enable any person or group to make an intelligent choice about whether or not the intervention should be inaugurated, continued, expanded or applied at a new site.

The method applies when the following conditions exist:

1. The resource costs of the intervention are quantifiable in dollars and are incurred in a reasonably brief span of time, that is, within a calendar year.

2. The positive outcomes are quantifiable in natural numbers; "graduates," job placements, and addiction-free days are examples.

3. The continuation of such outcomes into future years can be modeled according to a fairly simple rule. For example, the number of persons remaining in the jobs in which they were placed declines by $X \%$ per year; or "clean" addicts recidivate at $Y \%$ per year.

For real world situations, more often than not, these three conditions hold reasonably firmly. 
The exposition proceeds as follows: First, the mobility training program is described. Secondly, the framework of benefit cost analysis is explained. In the third section the concepts are applied to mobility training; in the fourth the threshold benefit is derived and compared to various cost measures. The input data section leads into the analysis of the results and the paper closes with a summary.

\section{PROGRAM BACKGROUND}

In the United States there are some three to five thousand agencies where developmentally disabled adults spend the day in supervised activities. The activities cover a broad spectrum including recreation, socializing, and counseling. However, the principal activity is usually "sheltered employment." These "work activity centers" normally pay a stipend to the clients for their work, which may or may not be covered by the value of what is produced. The justification for this intervention, particularly when it requires a subsidy, is its effect on the clients: that they are making incremental gains in marketable skills and that they feel useful from earning money which is theirs to spend. Normalization is a common term for the overall goal that encompasses this aim. Autonomy is my alternative term; the latter conveys the sense of personal control and self-direction that ideally flow from such participation. Graduation to unsheltered work is the aim for those clients able to make the shift, but for many, probably most, clients the degree of developmental disability prevents such a shift.

To participate in these activities, clients must commute to and from their home or group living quarters and the agency. The usual method is some form of assisted transportation. In 1981, under the sponsorship of the Michigan Department of Mental Health, the Wayne County Associations for the Retarded (WCAR), initiated a two-year program to train clients to gain greater independence in transportation, up to and including the unassisted use of public transportation for home to agency commuting. The training program involved pre- and posttests to assess clients' potential and progress, classroom teaching, visiting clients' homes, planning and taking roundtrip bus runs with clients, and monitoring solo runs (Hickman, Vilardo, Denniston, Alim, \& Dudley, 1984). The operational goals of the initial intervention were specified in terms of numbers or percentages of clients attaining various stages of the training by the degree of initial disability.

By the end of the first year of the program, October 1, 1982, twenty-six clients, $39 \%$ of the participants, had shifted from assisted to unassisted transportation. This resulted in the funding of a three pronged effort: (1) The continuation of the program at WCAR for a third year. (2) The replication of mobility training in several other sites to insure that the effectiveness of the intervention is not idiosyncratic to the initial WCAR site (that city/county, those clients or personnel). (3) The initiation of a study to compare the benefits and costs of mobility training to determine the valuc of its expansion to new sites. The author was responsible for the benefit cost analysis which is the focus of this paper.

\section{THE BENEFIT COST FRAMEWORK}

Evaluation in general and benefit cost analysis in particular are concerned with social choice. ${ }^{2}$ Rothenberg $(1975$, p. 56) characterizes every choosing situation as involving four distinct logical elements: alternatives, consequences, values and evaluation criteria.

Alternatives. The mutually exclusive alternatives in our problem are a mobility training program versus no program. There were no intentional variations in training methods (curriculum, number of supervised or solo rides, etc.) through time or across sites, so nothing is

\footnotetext{
${ }^{2}$ For a brief introduction to benefit cost analysis in the broader evaluation context, see, for example, Chapter 8 of Rossi and Frecman (1982). For book length introductory treatments, see Thompson (1980) and Levin (1983). A nonmathematical, brief, but excellent overview is Jerome Rothenberg (1975). For pedagogical purposes, there is no peer to the exposition cum example of Burton A. Weisbrod (1983). For a much more detailed exposition which assumes some familiarity with economic analysis, see Gramlich (1981).
}

known about the effectiveness of this mobility training effort relative to any possible alternatives. ${ }^{3}$ Staying with the basic training model seemed wise since the number of subjects was never sufficient to gain reliable estimates of the differential effect of any alteration in the program. However, this means we have no knowledge of what the effect on the outcome would be of using more or fewer resources (or alternative activity mixes). Therefore, we do not know whether this or an alternative training program is more cost-effective in terms of shifts to unassisted transportation per dollar spent. Rightly, given the number of clients, the focus was on evaluating one intervention, applied as uniformly as possible, against the status quo. In this respect our case is very similar to Weisbrod (1983); in his

\footnotetext{
${ }^{3}$ There certainly was a conscious increased effort to placate parents of clients, and/or enlist their more active cooperation, after the first year trial run at WCAR. See Ellis and Meadowcroft (1982).
} 
case hospitalization of the mentally ill is compared to one community treatment modality.

Consequences of the Intervention. A benefit cost analysis cannot proceed unless the consequences of the alternatives are known, that there was change which was due to the intervention itself (Rothenberg, 1975, p. 58). For mobility training, a shift from assisted to unassisted transportation was the intended consequence, and, for all sites and participants, whether that shift occurred is known. There are some qualitative results from interviews, 144 of 165 of the parents of WCAR clients believed the intervention had a positive effect on their son/daughter (Hickman et al., 1984, p. cxi). However, nothing else is known about any other subjective consequences of the training except what can be inferred from client behavior.

Is the shift due to the program? There was no specific comparison group to determine whether the shift from assisted to unassisted transportation was due to mobility training as such, in part because the pool of eligibles at the sites was not large enough to provide both experimentals and controls, and in part because the professionals judged that unassisted riding without training was simply not possible for their clients. Thus that the mobility training itself caused, or better, enabled the shifts is an assumption, probably a quite reasonable one.

Values. Benefit cost analysis is a weighing of desirable consequences relative to undesirable ones. This implies a value system or framework to distinguish the desirable from the undesirable, which is what is meant here by "point of view" (Rothenberg, 1975, p. 56). The point of view determines what are benefits and what are costs; it may be that of an individual (the client, the agency head, or even the analyst), a group (the client's family, a specific agency, a public transportation authority, taxpayers), or society as a whole.

In this analysis the point of view taken is that of society. Society is considered to care about the total net capacity to provide want-fulfillment and how that fulfillment is distributed. ${ }^{4} \mathrm{~A}$ benefit cost analysis from society's viewpoint is the equivalent of first separately carrying one out from each person's viewpoint, and then aggregating the results across individuals. Thus the subsidy of a line haul bus is a benefit to the riders and a cost to the taxpayers and is a wash from the social viewpoint.

Social costs are diminutions of the want-fulfillment of a society. A fundamental distinction is between tangible and intangible costs. Tangible costs are those which use up the resources available to produce valued

${ }^{4}$ The accuracy of this terminology is worth its awkwardness. It is Rothenberg's (1975, p. 59). goods and services; gasoline, equipment, human labor, and therefore time, are examples relevant to our analysis. Intangible costs are those which directly diminish satisfaction independent of tangible resource use. Anxiety and concern on the part of the parent of a developmentally disabled person at the fact or thought of their "child" travelling alone across the city exemplifies an intangible cost.

Social benefits are augmentations to want-fulfillment capacity. Conceptually they exactly parallel social costs, in fact a principal benefit of many interventions is a reduction in social costs (pollution control, for example). Tangible social benefits are any net increase in goods and services produced, whether produced by firm, government, or agency. If, for example, an agency trains a developmentally disabled person to assemble an appliance, this tangible social benefit is in the form of "human capital," an augmentation of the producing capacity of the society. Intangible benefits are direct increases in the satisfaction of society's members. An obvious relevant example is the increase in well-being of a developmentally disabled person from autonomy, from learning to travel independently and actually doing so.

Decision Criterion. If benefits and costs can be translated into dollars, they can be compared. This comparison is commonly called a decision criterion. Let $\boldsymbol{B}_{t}$ symbolize the dollar value of the benefits that will occur in time period $t$, a year in our example. Let $d$ symbolize the discount rate. Then, for a program returning benefits for $T$ years (the time horizon), we have:

$$
\begin{aligned}
\mathrm{PV}(B)= & B_{1} /(1+d)+B_{2} /(1+d)^{2}+\ldots \\
& +B_{t} /(1+d)^{t}+\ldots+B_{T} /(1+d)^{T}
\end{aligned}
$$

where $\mathrm{PV}(B)$ is the present value of the time stream of benefits, evaluated as of year zero. This discounting of benefits arises from the fact that, because resources are productive (that is, they could be invested in other projects), the returns from their use are progressively worth less the longer they are delayed. Let $C_{0}$ be the value of all the costs incurred in year zero. ${ }^{5}$ Then letting $V$ symbolize the net value of the program, we have:

$$
V=\mathrm{PV}(B)-C_{0}
$$

The usual decision criterion of benefit cost analysis is that if $\mathrm{V}$ is positive (and if all costs and benefits are included in $C_{0}$ and $\left.B_{t}\right)$, then the project should be

\footnotetext{
${ }^{5}$ If costs are incurred in more than one year, then PV(C) is the parallel concept. For our example all training is completed within one year, so $\operatorname{PV}(C)=C_{0}$.
} 
undertaken (relative to the status quo); or project $\mathrm{X}$ is better than project $\mathrm{Y}$ if the net value of $\mathrm{X}$ exceeds the net value of $\mathrm{Y}$. Taking a more modest view of the method, the value of $V$ should at least be one important element entering into the decision; distributional effects may also be relevant.

\section{THE COSTS AND BENEFITS OF MOBILITY TRAINING}

The true social cost of any activity is the value of any direct dissatisfaction plus the value of all resources used in that activity. The resources are to be valued at their "opportunity cost," whether an explicit expenditure of funds occurs or not. Translating this opportunity cost of resources into dollars is difficult whenever there are not explicit prices (including wages as the price of labor) that validly express the foregone alternative use. For example, evaluating the social cost of transportation is confounded by the (intentional) disparity between the fare and the true cost of resources used, and also by the social costs of congestion and pollution.

Training Costs. For each of three years of the WCAR program and for each of the replication sites, the budgets and expenditures were available. Expenditures were made on personnel, travel, supplies, equipment (WCAR only) and "other" (which was explicitly a space cost in one budget). Actual resource use may have been somewhat more or less than these expenditures. For example, non-budgeted personnel may have supervised or assisted in the training and/or the training personnel may have been occupied at times in unrelated activities. However, given that the program in all cases was sufficiently large that a specific person (or persons) was assigned full-time to training, there are good grounds to believe that the actual expenditures are reasonable estimates of actual resource use. Efforts to adjust the estimates were just as apt to distort as to improve them, so they were accepted as approximations of the tangible social costs of the training.

This decision is supported by the wide variability of total expenditures across sites in comparison to the narrower variability in expenditures per actual independent rider. Across the three replication sites, the range of total expenditures was $63 \%$ of the mean, $87 \%$ of the lowest total. The range of expenditures per independent rider was $15 \%$ of the mean, $17 \%$ of the lowest (calculated from Table 1). This is ground for assuming that agencies in other (Michigan) cities can train the developmentally disabled to be independent riders for approximately $\$ 2000$ per rider.

Time spent by clients in training was mainly devoted to actual commuting; only a small fraction was devoted to classroom instruction. Since they commuted regardless of the training, their time inputs were ignored. In only one site was a volunteer involved in training and it was not clear whether that helped or hindered the training. Therefore that person's time was also ignored.
Intangible Benefits. Imagine that we were able to obtain from everyone to whom it could conceivably be relevant an honest answer to the following question:

"How much would it be worth to you for 25 developmentally disabled persons to be trained to shift to commuting to sheltered workshops by public unassisted transportation?"6

The answers to this question would depend upon such characteristics as the following: whether the respondent expects to be a trainee, the income of the respondent, his/her knowledge of developmentally disabled persons and the degree to which the respondent cares about their autonomy. Were we to obtain valid answers to this question, the net dollar total of these answers would measure the net intangible social benefit (or cost!) of the training program. There is indirect evidence from the acquiescence of the public in the status quo that this would be worth some amount; otherwise why do we tolerate the subsidization of the sheltered workshops and assisted commuting to them?

Important as this question is, and the equivalent question for a myriad of human service interventions, we do not know the answers, nor do we have much hope of uncovering them, thus of knowing the dollar value of the intangible benefits. It is still possible, however, to estimate the tangible social benefits of the shift if it involves a reduction in tangible social costs, that is, if assisted transportation uses more resources than unassisted.

Tangible Benefits. The tangible benefit of mobility training is any reduction in tangible social cost, resulting from the client's shift from assisted to unassisted transportation. When the transportation of persons uses fewer resources, these savings are always potentially measurable in dollar terms. Yet, in any given situation, measuring them may be quite difficult, as may be determining to whom the savings accrue. Also the estimated savings from these sites may not be readily generalizable to new sites.

Assisted travel usually takes one of three forms: (1) private automobile, typically driven by an unpaid relative; (2) assisted public transportation, which is usu-

\footnotetext{
${ }^{6}$ The question is stated in its simplest possible form to focus attention on the basic point. To ensure that only intangible benefits (or costs) are included in the answer, the respondent should be asked to assume that training costs are just of fset by transportation savings. A great deal of clarification would be required to obtain valid answers: worth per year? Per trip? How long is the shift expected to last?
} 
ally portal-to-portal and may involve the use of special vehicles; (3) agency van, provided by the sheltered workshop or by some other agency. The successful completion of mobility training normally results in a shift from one of the above three forms of transportation to (4) unassisted public transportation provided by public line-haul bus service. The tangible social costs of each of these modes are the resources used which could otherwise be available for another valued use. For the vehicle they would include gas, oil, insurance, license, and actual depreciation of the vehicle. The social cost would also include the compensation of any employed operator or the opportunity cost of any volunteer operator (the dollar value of the time spent in doing what he/she would otherwise be doing). To these should be added congestion costs (which are very dependent upon time of day) and air pollution costs. For all of these costs there is abundant evidence that the social costs per passenger mile decline across modes from automobile to van to line haul bus. Hard information on costs beyond that ordering are difficult to come by and are almost certainly not generalizable to a new site. ${ }^{7}$

Determining what person or agency incurs what fraction of the cost of one or both modes of transportation is as confounding a problem. At any one replication agency, usually at least three of four of the following incurred transportation costs: the training agency, some other human service agency (often Community Mental Health), a public transportation agency with two or more modes, and a private automobile.

\section{THE THRESHOLD BENEFIT}

Given these difficulties in estimating the amount and incidence of the social costs of transportation, it was decided to turn the problem around to estimate as accurately as possible the threshold benefit, the minimum dollar value per round trip that would justify mobility training. The disadvantage of this method is that one cannot be sure that mobility training at an agency can be justified on resource grounds alone unless one can estimate the differential cost of unassisted versus assisted transportation of its particular clients. The advantages are first, that the threshold benefits derived are solidly defensible as good estimates, with no rough guesses added to muddy the water. Secondly, these estimates are useful, not only to the narrow perspective of reducing tangible transportation costs but also to the broader perspective that includes the intangible benefits from autonomy. The resulting estimates do not tell us the level of the benefits of mobility training, but do tell us what level the sum of tangible and intangible benefits must be above in order to justify mobility training.

We can conveniently conceptualize the benefits from mobility training in per commute (i.e., per round trip) terms. This will facilitate comparison with actual differential transportation costs, which normally will be formulated in dollars per trip. The benefits in any given year, $B_{t}$, equals the number of $\operatorname{commutes}^{8}$ per year (208) times the number of independent riders, $R_{t}$, times the benefit per commute, BEN. In equation form:

$$
B_{t}=208 * R_{t} * \mathrm{BEN}
$$

Next we need a simple method of modelling future rides. The number of riders in any given year is the total number who persevere, that is, the number in the previous year times the perseverance rate, $P$ :

$$
R_{t}=R_{t-1} * P
$$

This can be expressed in terms of initial programs participants and powers of the perseverance rate by the following procedure. The number of riders in the first year is the number of participants in the program, $N$, times the success rate, $s:^{9}$

$$
R_{1}=N * s
$$

The number in the second year is thus:

$$
R_{2}=R_{1} * P=N * s * P
$$

Likewise, for the third year:

$$
R_{3}=R_{2} * P=N * s * P^{2}
$$

\footnotetext{
${ }^{7}$ In the cities studied, reasonable guesstimates of the average cost of a two-run daily commute via automobile would be $\$ 8$ to $\$ 16$. (Cab cost in Michigan cities would be approximately \$14 including tip, using cab rates and using agency-supplied estimates of commute distances averaged over clients.) The cost would be lower if the opportunity cost of the driver were zero. For public unassisted transportation the social costs would be between $\$ 2$ and $\$ 5$, possibly higher. (One transportation authority reports $\$ 2.26$ as their average expenditure per trip.) None of these costs include pollution and congestion. Agency van cost would probably lie between the high public and low private, $\$ 5$ and $\$ 10$, difficult to estimate because of the potential uses of the van the remainder of the day.

${ }^{8}$ Deliberately conservative assumptions are made in deriving the expected number of unassisted round trips per year. First, unassisted trips made in the training year are ignored; only unassisted trips made after September 30 are counted. Secondly, it is assumed that only 208 round trips are made by the clients per year. This is an $80 \%$ attendance record.

${ }^{9}$ In the formula and text the number of actual unassisted riders is expressed as the number of participants times a success rate to empha. size that potential initiators of mobility training must guess that rate with reasonable accuracy; it varied considerably even across the replication sites. After the fact, of course, one can simply use the number of independent riders.
} 
In general then, for all $t$ between 1 and $T$ :

$$
R_{t}=N * s * P^{t-1}
$$

We can now restate total benefits in year $t$ as:

$$
B_{t}=208 * N * s * P^{t-1} * \mathrm{BEN}
$$

Substituting this into our earlier equation (1), the general expression for the present value of benefits, and gathering all the terms related to time, we have:

$$
\mathrm{PV}(B)=208 * N * s * \mathrm{BEN} * F
$$

where

$$
\begin{aligned}
F= & {\left[1 /(1+d)+P /(1+d)^{2}+P^{2} /(1+d)^{3}\right.} \\
& \left.+\ldots+P^{T-1} /(1+d)^{T}\right]
\end{aligned}
$$

The advantage of expressing PV $(B)$ in this way is that all the "messy" parts of the general expression are summarized into one term, which can be calculated independently. If we set the present value of benefits equal to total cost, so that $V=0$ in equation (2), and solve for the benefit per commute, BEN, we have the expression for the threshold benefit per commute:

$$
\text { THRESHOLD }=C_{0} /(208 * N * s * F)
$$

This formula allows us to calculate the threshold benefit directly from data on total cost, number of participants, the success rate, perseverance rate, discount rate and time horizon.

An intuitive understanding of this threshold benefit can be gained by relating it to simpler cost or cost-effectiveness measures. Consider the expression:

$$
C_{0} /(N * s)
$$

This is simply the cost per "success." For our case a "success" is an initial unassisted rider. The value of this cost effectiveness measure is approximately $\$ 2000$ in the replication sites. If "graduation" were all that society (or the decision maker) cared about, then this measure would itself be the threshold benefit.

We can also express costs in terms of commutes:

$$
C_{0} /(208 * N * s)
$$

is costs per independent commute (for commutes made in the first year after the training). This measure (which equalled approximately $\$ 10$ in the replication sites) is the value that each commute (first-year commute) would have had to equal or exceed for mobility training to have "paid off" in one year.

Our threshold benefit can be rewritten using this last expression divided by $F$ :

$$
\text { THRESHOLD }=\left[C_{0} /(208 * N * s)\right] / F
$$

The factor $F$ brings the $F u t u r e$ into the calculation. Since most initial riders will persevere beyond the first year, the true costs per all commutes (first year and later years) is well below the costs per firstyear commute, the expression in brackets. Were there no discounting $(d=0)$ and were all the successes to persevere to the planning horizon $(P=1)$, then $\mathrm{F}$ would be exactly equal to the time horizon, $T$. Both discounting and riders' "dropping out" (i.e., reverting back to assisted transportation) make $F$ lower than $T$.

\section{INPUT DATA}

From our expression for the threshold benefit, equation (4) above, we know our data requirements. We need to know the total cost of training, the number of participants and the success rate. Because success is apt to continue into the future, we also need the information in equation (3) to calculate $F$ : specific values for the perserverance rate, the discount rate, and the time horizon. Some of these data come from the demonstrations, but some are specific to the decision-maker (the discount rate) or the particular training agency (the time horizon). Taking the social perspective solves nothing. Economists who agree exactly on the definition of the social discount rate, disagree by wide margins on its actual value. Since the equation for the threshold ben- efit is relatively simple to solve for alternative values of all of its variables, this ambiguity about the proper values of particular variables can be turned into an advantage. The method allows one to perform an analysis of the sensitivity of the threshold benefit to alternative plausible values of every variable in its equation. We already have three demonstration sites (six "sites" counting WCAR's three years). Wherever a determinate value does not arise, alternative values are used, in particular, two definitions of success, two values of the discount rate, two values of the perseverance rate, and four (or seventeen) values of the time horizon. The multiplicity of resulting estimates of the threshold benefit both serves to satisfy a decision maker who comes to 
the problem with chosen values for variables and serves to show all decision makers the sensitivity of the estimate of the threshold to that choice.

Training Costs and Training Results. In Table 1 the basic data of the demonstrations are reported, the total costs of the training and the success of the training. In the first column actual expenditures for the one year of training are reported for the three replication sites and the annual expenditures of WCAR are reported for each of its grant years. The focus of attention should be on the three replication sites where all costs were training costs. The WCAR results are included to show how great the net gain from the shift to unassisted transportation would have to be to finance not only the training but all the other planning, start-up, and evaluation activities included in the WCAR budgets. The second column shows the total number of participants, those who entered mobility training, regardless of how far they progressed.

Levels of Success. The next three columns show the number of successes for three definitions of success. Although levels of successful training below what WCAR calls level III are important in terms of the client's sense of personal accomplishment and independence, level III is the most important. Passing it means that the client has successfully completed the prescribed number of accompanied and unaccompanied (monitored) bus trips. Only special reasons other than proven ability prevent such a graduate from being an unassisted traveler. (Typically the most common reason was departure from the agency.) What I have denominated Potential Independent Riders includes level III graduates who would be using unassisted transportation were it not for the refusal of parent or guardian to allow it. Since these clients are otherwise judged to be able to so travel, there is some justification for shifting the cost of assisted transportation to the refuser. Actual independent riders are those who began to travel unassisted during the training (and budget) year and continued to do so into the next year.

The right hand three columns of Table 1 show that there has been considerable variability of success rates across time for WCAR and across the three replication sites. At WCAR the problem of parental refusal was very important in the first year since of the $\mathbf{4 8}$ potential riders only 26 became actual, but has apparently disappeared in the most recent training year. Between the three replication sites there is considerable variation, particularly in the last and most important column. One site has a $73 \%$ success rate in transforming clients into actual independent riders, while another had only a $46 \%$ rate.

The Perseverance Rate. Clearly the benefits of the shift from assisted to unassisted transportation will last beyond the first year after training for many of the clients, but we should expect that not all will so continue, for whatever reasons, including departure from the agency. From many points of view, a client who leaves the training agency but continues to use unassisted transportation should continue to be counted a success. They cannot be so counted here since their ride status is unknown. Fortunately the three years of experience of WCAR provide sufficient information from their follow-ups to make two defensible estimates of the perseverance rate. Of the 26 clients who graduated to unassisted travel at WCAR by September 30, 1982, $\mathbf{2 1}$, or $\mathbf{8 0 . 8 \%}$, were still at the agency riding unassisted

TABLE 1

MOBILITY TRAINING COST AND OUTCOMES

\begin{tabular}{|c|c|c|c|c|c|c|c|c|}
\hline \multirow[b]{3}{*}{ Site } & \multirow[b]{3}{*}{ Total cost } & \multirow[b]{3}{*}{$N^{a}$} & \multicolumn{3}{|c|}{ Number of persons } & \multicolumn{3}{|c|}{$\begin{array}{l}\text { Percent of participants } \\
\text { (success rate) }\end{array}$} \\
\hline & & & \multirow[b]{2}{*}{ Level III' } & \multicolumn{2}{|c|}{ Independent riders } & \multirow[b]{2}{*}{ Level II $^{\mathrm{b}}$} & \multicolumn{2}{|c|}{ Independent riders } \\
\hline & & & & Potential & Actual & & Potential & Actual \\
\hline Detroit & $\$ 33,785$ & 22 & 16 & 16 & 16 & $73 \%$ & $73 \%$ & $73 \%$ \\
\hline Kalamazoo & 20,000 & 24 & 16 & 13 & 11 & 67 & 54 & 46 \\
\hline Muskegon & 25,518 & 19 & 16 & 15 & 12 & 84 & 79 & 63 \\
\hline \multicolumn{9}{|l|}{ WCAR } \\
\hline Year 1 & 113,704 & 67 & 49 & 48 & 26 & 73 & 72 & 39 \\
\hline Year 2 & 130,627 & 60 & 41 & 38 & 30 & 68 & 63 & 50 \\
\hline Year 3 & 134,804 & 42 & 28 & 23 & 23 & 67 & 55 & 55 \\
\hline
\end{tabular}

Note. Total costs are taken from the Financial Status Reports supplied by the agencies to the Michigan Department of Mental Health. Client statistics for the three reapplication sites are from Appendix III, for the three WCAR years from Appendix A, of Hickman, et al. (1984). a $N=$ Number of participants.

'Graduated from Level III of mobility training. 
two years later, in October, 1984. This yields an annualized perseverance rate of .899 for this group $(.808=$ $.899 * .899)$. Of the 30 clients who graduated to unassisted transportation in the next year (the 12 months from October 1,1982 to September 30,1983 ) 28 , or $93.3 \%$, were still at the agency riding unassisted one year later, in October, 1984. Although I believe that the argument is persuasive that the perseverance rate for the second group is a better estimate of what future trainees will experience, subsequent calculations are made using both .899 and .933 as estimates of the perseverance rate. ${ }^{10}$ However, using .899 still serves as a sensitivity test.

The Time Horizon. The time horizon is that date in the future after which no benefits occur or are counted. There are arguments pro and con about how long a time horizon should be assumed. When the analysis assumes that the number of independent riders will diminish each year by 7 or $10 \%$ (100 minus the percentage persevering), one can argue that a very long time horizon should be incorporated. On the other hand, agen- cies do go in and out of existence, and even more so, programs; furthermore, whatever organization expects the accrued benefits may be impatient or skeptical about long delayed benefits. In the calculations in the tables, I have adopted a reasonable range of horizons, from 4 to 12 years; in order to provide a decision framework for any agency considering adopting mobility training, $I$ include every time horizon between one year and seventeen years in calculating possible $F$ 's (provided in Table A.1 of the Appendix).

The Discount Rate. The analysis assumes that the threshold benefit is in 1984 dollars, mainly on the reasonable ground that inflation is not likely to be worse for the cost of unassisted transportation then it will be for assisted transportation. The discount rate, which expresses the degree to which future dollars are worth less than present dollars, is also in (1984) real, not nominal dollars. A rate of five percent is reasonable in my judgment, but the alternative rate of $10 \%$ is also used in calculating the threshold benefit.

\section{RESULTS}

The threshold benefits for WCAR (by year) and for the three replication sites are calculated in straightforward fashion using the formulas for THRESHOLD in equation (4) and for $F$ in equation (3). The values for $C_{0}$, $N$, and $s$ are specific to the site and are taken from the appropriate row of Table 1; for example, those values are $\$ 33,785,22$, and .73 for the Detroit site (when only actual independent riders are counted as successes). The discount rate, perseverance rate, and time horizon $(d$, $P$, and $T$ ), must be chosen; once chosen they determine $F$. Its value may be calculated using its formula, or for representative values, may be looked up in Table A.1. For example, for $d=5 \%, P=.933$ and $T=12$, from Table A.1, we find that $F=6.476284$. Thus, the corresponding value of the threshold benefit for the Detroit site is:

\footnotetext{
${ }^{10}$ The model underlying the calculations in the text assumes that the same percentage of initial riders persevere between every pair of years, between the first and second and between the fourth and fifth, etc. This means that the number of independent riders is assumed to steadily decline. A more realistic model, in my judgment, would be one in which the rate of perseverance rises through time to some plateau less than one, because successful independent traveling is probably selfreinforcing. If a constant rate is used because we do not yet have sufficient follow-up to know the rate of increase in the perseverance rate through time then the higher perseverance rate seems preferable. Secondly, there is every reason to believe that the experience of the first year WCAR participants was strongly affected by the developmental character of the program. Both of these arguments lead to using .933 rather than .899 as the perseverance rate.
}

$$
\begin{aligned}
\text { THRESHOLD } & =33,785 /(208 * 22 * .73 * 6.47284) \\
& =\$ 1.56
\end{aligned}
$$

Table 2 displays the results for cach of the replication sites and the three WCAR years for actual independent riders. In the table the threshold benefit is calculated for several time horizons and both discount rate assumptions. The more favorable perseverance rate (.933) is assumed. The calculations for the less favor-

TABLE 2.

\begin{tabular}{|c|c|c|c|c|c|c|}
\hline \multirow[b]{3}{*}{ Site } & \multirow{3}{*}{$\begin{array}{l}\text { Actual } \\
\text { independent } \\
\text { riders }\end{array}$} & \multicolumn{3}{|c|}{$\begin{array}{l}10 \% \text { Discount } \\
\text { rate }\end{array}$} & \multicolumn{2}{|c|}{$\begin{array}{l}5 \% \text { Discount } \\
\text { rate }\end{array}$} \\
\hline & & \multicolumn{5}{|c|}{$\begin{array}{l}\text { Time horizon } \\
\text { (years) }\end{array}$} \\
\hline & & 4 & 8 & 12 & 6 & 12 \\
\hline Detroit & 16 & $\$ 3.51$ & $\$ 2.32$ & $\$ 1.97$ & $\$ 2.34$ & $\$ 1.56$ \\
\hline Kaiamazoo & 11 & 3.03 & 1.99 & 1.69 & 2.01 & 1.35 \\
\hline Muskegon & 12 & 3.54 & 2.33 & 1.98 & 2.36 & 1.58 \\
\hline \multicolumn{7}{|l|}{ WCAR } \\
\hline Year 1 & 26 & 7.28 & 4.80 & 4.08 & 4.84 & 3.25 \\
\hline Year 2 & 30 & 7.25 & 4.77 & 4.06 & 4.82 & 3.23 \\
\hline Year 3 & 23 & 9.75 & 6.43 & 5.46 & 6.49 & 4.35 \\
\hline
\end{tabular}

THRESHOLD BENEFIT: ACTUAL INDEPENDENT RIDERS

Note. The more favorable perseverance rate $(.933)$ is used in the calculation of these threshold benefit levels. 
able perseverance rate $(.899)$ are reproduced as Appendix Table A.3.

For the three replication sites, the threshold benefit is sufficiently low under most pairs of assumptions to insure that mobility training can be justified on costsaving grounds alonc. Most of these threshold bencfits are below $\$ 2.50$, and only reach the $\$ 3+$ range for the very short 4 -year time horizon. ${ }^{11}$

If the differential tangible cost of assisted over unassisted transportation is greater than $\$ 2$, then all the replication sites should continue mobility training (unless they have extremely short time horizons). That deci- sion is easy. (Of course, the pool of clients trainable to be independent riders could be too small in a given agency.) A new agency should certainly consider mobility training if it thinks it can approximate or better the success of these replication sites. If it investigates and finds the differential tangible cost (of assisted over unassisted transportation) is $\$ 2$ or more, it should almost certainly inaugurate mobility training. If the differential cost is third party borne, then these results may help the agency convince the third party that it should, from self-interest alone, finance a mobility training project.

\section{CONCLUSION}

The concepts, methodology, and procedures of benefit cost analysis have been applied to the difficult but common case where the translation of benefits into dollars is problematic. This has been done by focusing on the "threshold benefit," the value the benefit must equal or exceed to justify the program. The derivation of the threshold benefit from the benefit cost model showed explicitly all the assumptions which enter any benefit cost analysis. The ease with which the threshold benefit can be calculated encourages sensitivity analysis, which was used in our example. This, in turns, allows the reader or decision maker to choose when somewhat arbitrary choices must be made (for example, about $d$ and $T$ ).
The threshold benefits estimated in the example are low enough to suggest that mobility training of the developmentally disabled may be warranted in terms of transportation cost saving. Furthermore, the threshold benefit estimates of our example should force agencies, funders and the public to go beyond tangible benefits, to ask what is the value of the directly enjoyed improvement in clients' well-being, in our example, the value of greater autonomy of developmentally disabled persons. The methodology should be broadly applicable since difficulties in measuring benefits in dollars is the main stumbling block to benefit cost analysis, especially for human services.

\section{REFERENCES}

ELLIS, E., \& MEADOWCROFT, J.W. (1982). Mobility training for work activity centers. Dearborn Heights, MI: Wayne County Associations for the Retarded.

GRAMLICH, E.M. (1981). Benefit cost analysis of government programs. Englewood Cliffs, NJ: Prentice-Hall.

HICKMAN, B.B., VILARDO, S., DENNISTON, K., ALIM, D., \& DUDLEY, T. (1984). D.D. mobility truining progrum: Final report. Dearborn Heights, MI: Wayne County Associations for the Retarded.

\footnotetext{
"The threshold benefit levels for WCAR are relatively high; this is to be expected given that much of the costs at this site were not training costs. In spite of these nontraining costs, however, a time horizon of 12 years results in a threshold benefit, $\$ 3$ to $\$ 4$, that is probably sufficiently low to be met by the differential cost between, say, van versus line haul transportation.

If we include level III graduates who continue to be assisted solely because of parental refusal, then all training site/years except Detroit and WCAR (Year 3) have even lower threshold benefit levels than those in Table 2. (See Table A.2 of the Appendix.)
}

LEVIN, H.M. (1983) Cost-effectiveness: A primer: Vol. 4. New perspectives in evaluation. Beverly Hills, CA: Sage Publications.

NAGEL, S.S. (1983). Dealing with unknown variables in policy/program evaluation. Evaluation and Program Planning, 6, 7-18.

ROSSI, P.H., \& FREEMAN, H.E. (1982). Evaluation: A systematic approach (2nd ed.). Beverly Hills, CA: Sage Publications.

ROTHENBERG, J. (1975). Cost-benefit analysis: A methodological exposition. In M. Guttentag \& E. Streuning (Eds.), Handbook of Evaluation Research, Vol. 2 (pp. 55-81). Beverly Hills, CA: Sage Publications.

THOMPSON, M.S. (1980). Benefit cost analysis for program evaluation. Beverly Hills, CA: Sage Publications.

WEISBROD, B.A. (1983). An experiment in treating the mentally ill: A guide to benefit cost analysis. Chapter 6 of his Economic and Medical Research. Washington, DC: American Enterprise Institute. 


\section{APPENDIX}

TABLE A. 1

VALUES OF TIME FACTOR DIVISORS ("F's") FOR VARIOUS VALUES OF THE PERSEVERANCE RATE, DISCOUNT RATE, AND TIME HORIZON

\begin{tabular}{cccccc}
\hline & \multicolumn{2}{c}{ Discount rate: $5 \%$} & & \multicolumn{2}{c}{ Discount rate: $10 \%$} \\
\cline { 2 - 3 } \cline { 5 - 6 } $\begin{array}{c}\text { Time } \\
\text { horizon } \\
\text { (years) }\end{array}$ & \multicolumn{2}{c}{ Perseverance rate } & & \multicolumn{2}{c}{ Perseverance rate } \\
\cline { 2 - 3 } \cline { 5 - 6 } 1 & .933 & .899 & & .899 & .933 \\
2 & .952381 & .952381 & & .909091 & .909091 \\
3 & 1.798639 & 1.767800 & & 1.652066 & 1.680165 \\
4 & 2.550601 & 2.465955 & & 2.259279 & 2.334177 \\
5 & 3.218772 & 3.063708 & & 2.755538 & 2.888897 \\
6 & 3.812490 & 3.575499 & & 3.161117 & 3.359401 \\
7 & 4.340050 & 4.013689 & & 3.492586 & 3.758474 \\
8 & 4.808826 & 4.388863 & & 3.763486 & 4.096960 \\
9 & 5.225366 & 4.720084 & & 3.984885 & 4.384058 \\
10 & 5.594921 & 4.985110 & & 4.165829 & 4.627569 \\
11 & 5.924375 & 5.220584 & & 4.313709 & 4.834111 \\
12 & 6.216611 & 5.422196 & & 4.434568 & 5.009296 \\
13 & 6.476284 & 5.594813 & & 4.533342 & 5.157885 \\
14 & 6.707022 & 5.742607 & & 4.614068 & 5.283915 \\
15 & 6.912049 & 5.869146 & & 4.680043 & 5.390811 \\
16 & 7.094230 & 5.977488 & 4.733962 & 5.481479 \\
17 & 7.256111 & 6.070249 & 4.778029 & 5.558382 \\
& 7.399542 & 6.149671 & 4.814044 & 5.623609 \\
\hline
\end{tabular}

TABLE A.2 THRESHOLD BENEFIT: POTENTIAL INDEPENDENT RIDERS

\begin{tabular}{|c|c|c|c|c|c|c|}
\hline \multirow[b]{3}{*}{ Site } & \multirow{3}{*}{$\begin{array}{c}\text { Potential } \\
\text { independent } \\
\text { riders }\end{array}$} & \multicolumn{3}{|c|}{$\begin{array}{c}10 \% \text { Discount } \\
\text { rate }\end{array}$} & \multicolumn{2}{|c|}{$\begin{array}{l}5 \% \text { Discount } \\
\text { rate }\end{array}$} \\
\hline & & \multicolumn{5}{|c|}{$\begin{array}{c}\text { Time horizon } \\
\text { (years) }\end{array}$} \\
\hline & & 4 & 8 & 12 & 6 & 12 \\
\hline Detroit & 16 & $\$ 3.51$ & $\$ 2.32$ & $\$ 1.97$ & $\$ 2.34$ & $\$ 1.56$ \\
\hline Kalamazoo & 13 & 2.56 & 1.69 & 1.43 & 1.70 & 1.14 \\
\hline Muskegon & 15 & 2.83 & 1.87 & 1.59 & 1.88 & 1.26 \\
\hline \multicolumn{7}{|l|}{ WCAR } \\
\hline Year 1 & 48 & 3.94 & 2.60 & 2.21 & 2.62 & 1.76 \\
\hline Year 2 & 38 & 5.72 & 3.77 & 3.20 & 3.81 & 2.55 \\
\hline Year 3 & 23 & 9.75 & 6.43 & 5.46 & 6.49 & 4.35 \\
\hline
\end{tabular}

Note. The more favorable perseverance rate $(.933)$ is used in the calculation of these threshold benefit levels.
TABLE A.3

THRESHOLD BENEFIT: ACTUAL INDEPENDENT RIDERS (ASSUMES UNFAVORABLE PERSEVERANCE)

\begin{tabular}{|c|c|c|c|c|c|c|}
\hline \multirow[b]{3}{*}{ Site } & \multirow{3}{*}{$\begin{array}{l}\text { Actual } \\
\text { independent } \\
\text { riders }\end{array}$} & \multicolumn{3}{|c|}{$\begin{array}{l}10 \% \text { Discount } \\
\text { rate }\end{array}$} & \multicolumn{2}{|c|}{$\begin{array}{l}5 \% \text { Discount } \\
\text { rate }\end{array}$} \\
\hline & & \multicolumn{5}{|c|}{$\begin{array}{c}\text { Time horizon } \\
\text { (years) }\end{array}$} \\
\hline & & 4 & 8 & 12 & 6 & 12 \\
\hline Detroit & 16 & $\$ 3.68$ & $\$ 2.55$ & $\$ 2.24$ & $\$ 2.53$ & $\$ 1.81$ \\
\hline Kalamazoo & 11 & 3.17 & 2.19 & 1.93 & 2.18 & 1.56 \\
\hline Muskegon & 12 & 3.71 & 2.57 & 2.26 & 2.55 & 1.83 \\
\hline \multicolumn{7}{|l|}{ WCAR } \\
\hline Year 1 & 26 & 7.63 & 5.28 & 4.64 & 5.24 & 3.76 \\
\hline Year 2 & 30 & 7.60 & 5.25 & 4.62 & 5.22 & 3.74 \\
\hline Year 3 & 23 & 10.23 & 7.07 & 6.22 & 7.02 & 5.04 \\
\hline
\end{tabular}

Note. The less favorable perseverance rate $(.899)$ is used in the calculation of these breakdown benefit levels. 